\title{
Mitomycin-C Use in Ophthalmology
}

\author{
Parul Singh ${ }^{1}$, Abhishek Singh ${ }^{2}$ \\ ${ }^{1}$ Department of Ophthalmology, Veer Chandra Singh Garhwali Government Medical Science and \\ Research Institute, Srinagar Garhwal, Uttarakhand, India. \\ ${ }^{2}$ Department of Radiotherapy and Clinical Oncology, Veer Chandra Singh Garhwali Government \\ Medical Science and Research Institute, Srinagar Garhwal, Uttarakhand, India.
}

\begin{abstract}
Mitomycin-C is a chemotherapeutic drug that acts by inhibiting DNA synthesis. Its use and application in ophthalmology has been increasing in recent years because of its mandatory effects on wound healing. Current applications include pterygium surgery, glaucoma surgery, corneal refractive surgery, cictracial eye disease, conjunctivalneoplasia, dacryocystorhinostomy surgeries and allergic eye disease. This article reviews the current trends and uses of mitomycin-C in the eye and its related complications.
\end{abstract}

Key Words:Mitomycin-C, Ophthalmology, eye diseases.

\section{Introduction:}

Mitomycin-C (MMC) is an anti-neoplastic/ antibiotic agent isolated from soil bacterium Streptomyces caespitosus. It is used intravenously to treat upper gastro-intestinal tumors, anal cancer, breast cancer and bladder tumors. Mitomycin $\mathrm{C}$ has also been used topically rather than intravenously in several areas like bladder cancers and intra-peritoneal tumors. It is now well known that a single instillation of this agent within 6 hours of bladder tumor resection can prevent recurrence.In esophageal and tracheal stenosis application of MMC onto the mucosa immediately following dilatation will decrease restenosis by decreasing the production of fibroblasts and scar tissue. In eye surgery, it is applied topically to prevent recurrence in pterygium surgery, to prevent scarring during glaucoma filtering surgery and haze after Photorefractive keratectomy (PRK) or lasik. MMC was first used in ophthalmology in 1969 in Japan, where recurrent pterygium were successfully treated with the drug [1]. Its use and application in ophthalmology has been increasing in recent years because of its modulatory effects on wound healing.

\section{Pharmacology and mechanism of action:}

It is an anti-metabolite with anti-proliferative effect on cells showing the highest rate of mitosis by inhibiting DNA synthesis and interferes with RNA transcription and protein synthesis. DNA is inhibited by cross linking at the $\mathrm{N}$ position of Adenine and at 06 and $\mathrm{N}$ position of Guanine. The cell cycle is most affected during the late G-I and early S-phase. The chemical formula is $\mathrm{C}_{15} \mathrm{H}_{18} \mathrm{~N}_{4} \mathrm{O}_{5}$.

\section{Drug Reconstitution And Pharmacokinetics:}

The drug is available in a vial $(2 \mathrm{mg} / \mathrm{ml})$. It is further reconstituted with normal saline $(5 \mathrm{ml})$ to make $0.4 \mathrm{mg} / \mathrm{ml}$ or in $10 \mathrm{ml}$ to make $0.2 \mathrm{mg} / \mathrm{ml}$. the drug should be stored under refrigeration after reconstitution to preserve its potency and under these conditions; it is potent for a period of two weeks only. MMC is delivered in solubilized form. It has high bio-availability in the target tissue because of its hydrophobic character, which favors its penetration into the epithelially denuded cornea and conjunctiva, while deterring its movement into or through intact epithelium [1].

\subsection{Clinical uses of Mitomycin C in Ophthalmology:}

- Pterygium surgery

- Glaucoma filtering surgery

- Refractive surgeries

- Ocular surface tumors

- Squint surgeries

- Dacryocystorhinostomy (DCR)

- Allergic conjunctivitis. 


\section{Pterygium Surgery}

The pterygium is a horizontally oriented, triangular growth of abnormal tissue that invades the cornea from a base in the canthal region of the bulbar conjunctiva.Dose: $0.2-0.4 \mathrm{mg} / \mathrm{ml}$ applied intra-operatively over bare sclera for 1-5 minutes. Among the most impressive results with pterygium were double masked, prospective trial using doses of $0.4 \mathrm{mg} / \mathrm{ml}(0.04 \%)$ and $1 \mathrm{mg} / \mathrm{ml}$ four times daily for two weeks; they showed a recurrence rate of $2.2 \%$ compared with the placebo rate of $88.9 \%$ after 5 months of follow up [2]. Other reports also describe good results with no serious complications using $0.2 \mathrm{mg} / \mathrm{ml}$ of Mitomycin-C [3]. A detailed report of 10 cases with serious, vision-threatening complications associated with Mitomycin-C use after pterygium surgery has been published when a concentration of $0.4 \%$ was used post-operatively for up to 3 weeks [4]. Complications:Secondary glaucoma, corneal melting and perforation corneal edema, scleral calcification. Other complications of MMC in pterygium surgery include pain, excessive tearing, prolonged hyperemia, late hemorrhage, chemosis, lid edema, ptosis, wound dehiscence, photopobia, corneal blood staining, pigment accumulation, superficial punctate keratitis and delayed wound healing.

\subsection{Glaucoma filtering surgery:}

The high failure rate of trabeculectomy surgery is partly due to subconjunctival or scleral scarring at bleb. MMC inhibits the fibroblasts proliferation and subsequent scarring of filtration bleb. Intraoperative MMC applied at concentration of $0.2 \mathrm{mg} / \mathrm{ml}$ controlled post-operative intra-ocular pressure (IOP) as effectively as a $0.4 \mathrm{mg} / \mathrm{ml}$ concentration in high risk cases of congenital glaucoma, but with lower incidence of complications and thin walled blebs [5].No significant difference was seen in overall success or complication between subconjunctival and intra-scleral application of MMC augmented trabeculectomies in glaucomatous eyes at high risk of surgical failure [6].In selected pediatric cases of primary or secondary glaucoma in which visualization of the trabecular meshwork is poor trabeculectomy augmented with MMC and 5-FU is a good treatment option [7].

\subsection{Dosage: $0.02-0.04 \%$}

Method:Merocel sponge soaked in the desired concentration is kept for 1-5 minutes generally subconjunctival and sometimes subscleral. It is then thoroughly washed with balanced salt solution.Complications: Development of thin walled cystic blebs, late bleb leaks, bleb infections, endophthalmitis, chronic hypotony, hypotonic maculopathy and corneal epithelial toxicity.

\subsection{Refractive Surgeries:}

Haze formation with loss of corneal transparency and surface irregularities and myopic regression are the major complications after corneal refractive surface surgery. The use of Mitomycin-C with its antibiotic and anti-neoplastic properties is intended to inhibit wound healing mechanisms leading to sub-epithelial fibrosis [8]. It is usually applied at a concentration of $0.2 \mathrm{mg} / \mathrm{ml}(0.02 \%)$ for 12 to 120 seconds over the ablated stroma, although some studies suggest that lower concentrations $(0.01 \%, 0.002 \%)$ could also be effective in preventing haze when treating low to moderate myopia. This dose of MMC has not been associated with any clinically relevant epithelial corneal toxicity [9]. Single application of diluted MMC $0.02 \%$ solution following scraping of the corneal surface was effective and safe in treating haze and regression after PRK for myopia [10].

\subsection{Ocular surface tumors}

Ocular surface tumors include a variety of neoplasms originating from squamous epithelium, melanocytes, and lymphocytic resident cells of the conjunctivalstroma. MMC selectively inhibits DNA synthesis. Topical MMC can treat satellite and multifocal lesions and the entire ocular surface [11]. Topical MMC $0.4 \mathrm{mg} / \mathrm{ml}(0.04 \%)$ is administered four times a day for three weeks [12]. It has been used successfully as adjunctive therapy for controlling conjunctival and corneal squamous cell carcinoma even in extensive recurrent disease [13].

\subsection{Squint surgeries:}

- Topical Mitomycin-Cmay enhance the success rate of strabismus surgery with delayed adjustment and reduce post-operative adhesions [14]. Intra-operative application of MMC is reported in cases of restrictive squints. It helps to reduce fibrosis and scarring under the tenons layer [15].

Dose: $0.2 \mathrm{mg} / \mathrm{ml}$ for 5 minutes between the conjunctiva and the sclera after adhesion release.

\section{Dacryocystorhinostomy}

The most important cause of failure of DCR surgery is fibrosis occurring under the flaps near the osteotomy sites. MMC inthese cases tends to suppress fibrous proliferationand scar formation. Intra-operative 
MMC application is effective in increasing the success rate of DCR surgery and no significant complications resulted from its use [16]. The non-patency rate in the MMC group is $4.5 \%$ compared to $11.4 \%$ in the

conventional group. A piece of cotton soaked with $0.2 \mathrm{mg} / \mathrm{ml} \mathrm{MMC} \mathrm{is} \mathrm{applied} \mathrm{to} \mathrm{the} \mathrm{osteotomy} \mathrm{site} \mathrm{for} 30$ minutes intra-operatively is effective in maintaining a larger osteotomy size and also improves success rates over the traditional DCR procedure [17].

Dose: 0.02 to $0.04 \%$ for $5-30$ minutes.

Allergic conjunctivitis :In a study topical MMC $(0.2 \mathrm{mg} / 10 \mathrm{ml})$ was applied four times a day for 3 months and was found to be safe and effective alternative to topical azelastine, in treating allergic conjunctivitis.

Ocular complications of topical Mitomycin C:Minor complications like ocular pain, photophobia, lacrimation, lid edema, foreign body sensation (secondary to superficial punctate keratitis). Major complications are rare include scleral ulceration, necrotizing scleritis, perforation, uveitis, cataract, glaucoma and symblepharon formation.

\section{Conclusion:}

The use of topical Mitomycin C in ophthalmology is increasing in every subspeciality but risk benefit ratio should be considered, keeping in mind its complications. The dose and duration of application of MMC depends on surgery in which it is being used but is still controversial. Trials with longer follow up are required to establish safety and efficacy of drug.

\section{References:}

[1]. Kunitomoro N, Mori S. Studies on pterygium:Part 4,a treatment of pterygium by Mitomycin-C installation. ActaSocOphthalmolJpn 1969;67:601-7.

[2]. Singh G, Wilson MR, Foster CS. Mitomycin -C eye drops as treatment for pterygium.Ophthalmology 1998;95:813-21.

[3]. Hayasaka S, Noda S, Yamamoto Y. Postoperative instillation of low-dose mitomycin C in the treatment of primary pterygium. Am J Ophthalmol 1988; 106:715.

[4]. Rubinfeld RS, Stein RM. Serious complications of topical mitomycin- C after pterygium surgery. Ophthalmology 1992;99: 164754.

[5]. Agarwal HC, Sood NN, Sihota R, Sanga L, Honavar SG Mitomycin-C in congenital glaucoma Ophthalmic Surg Lasers. 1997 Dec;28(12):979-85.

[6]. Harish C Agarwal, DeepaliSaigal, RamanjitSihota Assessing the role of subconjunctival versus intrascleral application of Mitomycin-C in highrisk trabeculectomies, Indian journal of ophthalmology, Year : 2001 Volume : 49 | Issue : 2 |Page : 91 -95

[7]. R Ehrlich, M Snir, M Lusky, D Weinberger, R Friling, and D DGaton Augmented trabeculectomy in paediatric glaucoma Br J Ophthalmol.2005 February; 89(2): 165-168.

[8]. Kottler UB, Dick HB. [Mitomycin C in refractive corneal surface surgery with the eximerlaser : first experience and review of the literature].[Article in German] KlinMonblAugenheilkd. 2005 Jun;222(6):499-504.

[9]. Teus MA, de Benito-Llopis L, Alió JL Mitomycin C in corneal refractive surgery.SurvOphthalmol. 2009 Jul-Aug;54(4):487-502.

[10]. Vigo L, Scandola E, Carones F Scraping and mitomycin C to treat haze and regression after photorefractive keratectomy for myopia. J Refract Surg. 2003 Jul-Aug;19(4):449-54.

[11]. Salmon SE, Sartorelli AC. Cancer chemotherapy.In: Katzung BG, editors.Basic and clinical pharmacology. 6th ed. Norwalk, CT: Appleton and Lange; 1995.Chap.56.

[12]. Hirst LW. Randomized controlled trial of topical mitomycin C for ocular surface squamous neoplasia: Early resolution. Ophthalmology 2007;114:976-82.

[13]. Shields CL, Naseripour M, Shields JA. Topical mitomycin C for extensive,recurrentconjunctival-corneal squamous cell carcinoma.Am J Ophthalmol 2002;133:601-6.

[14]. Oh SO, Chang BL, Lee J. Effects of mitomycin C on delayed adjustment in experimental strabismus surgery.Korean J Ophthalmol. 1995 Jun;9(1):51-8.

[15]. Chen PL, Chen WY, Lu DW.Evaluation of mitomycin C in reducing postoperative adhesions in strabismus surgery. J OculPharmacolTher 2005;21:406-10.

[16]. S. Liao, S. KaoJ. Tseng, M. Chen, and P. Hou, Results of intraoperative mitomycin C application in dacryocystorhinostomy Br J Ophthalmol. 2000 August; 84(8): 903-906.

[17]. Kao SC, Liao CL, Tseng JH, Chen MS, Hou PK. Dacryocystorhinostomy with intraoperative mitomycin C. Ophthalmology 1997; 104:86-91. 